\title{
Meaning of Life in Cancer Patients Associated with Demographic and Clinical Characteristics
}

\author{
M Chehrehgosha ${ }^{1}$, A Sanagu ${ }^{2}$, A Mohammadi $^{3}$, AR Shahmirzadi ${ }^{3}$
}

\begin{abstract}
Objective: The aim of this study was to examine the meaning of life in cancer patients and its association with clinical and demographic characteristics.

Methods: This cross-sectional study comprised 150 patients who were referred to the department of oncology and radiotherapy centre of 5-Azar teaching Hospital (Gorgan). All eligible patients were seen during five months in 2013. Data were collected by use of MiLs questionnaire (Meaning in Life Scale). The instrument consists of four domain: harmony and peace, life perspective, confusion and lessened meaning and benefits of spirituality, which contain of 21 questions. Total Meaning scores range between -3 to 17, the higher points, represent the favourable meaning of life (more positive view about life). The reliability coefficient Cronbach's alpha (0.87) was calculated. Statistical Package for the Social Sciences (Spss) software (version 18) was used for analysis and independent t-test and the one-way analysis of variance (ANOVA) were applied. The significance level for this test was considered 0.05 .

Results: The mean age of patients was $48.31 \pm 5.1$ years. A total of 47.3 per cent of patients were males. Fifty-two per cent were urban residents, 34 per cent of those illiterate and 78.7 per cent of participants were married. Average score of meaning of life was $7.18 \pm 1.99$ from 17 scores. Marital status ( $\mathrm{p}<$ 0.029), type of treatment regimen $(\mathrm{p}<0.012)$, number of children $(\mathrm{p}<0.018)$ and place of residence $(\mathrm{p}$ $<0.046)$ are statistically, meaning significant full relationship with total score of meaning of life.

Conclusion: Meaning of life of all participating in study was relatively good, which may be caused by the Islamic culture, so rich in concepts of meaning of life in all areas of life (health and disease).
\end{abstract}

Keywords: Cancer patients, meaning of life, spirituality, survivor

\section{EI Sentido de la Vida en Pacientes con Cáncer Asociado a Características Demográficas y Clínicas}

\author{
M Chehrehgosha ${ }^{1}$, A Sanagu ${ }^{2}$, A Mohammadi $^{3}$, AR Shahmirzadi ${ }^{3}$
}

\begin{abstract}
RESUMEN
Objetivo: El objetivo de este estudio fue examinar el significado de la vida en pacientes con cáncer y su asociación con características clínicas y demográficas.

Métodos: Este estudio transversal compuesto por 150 pacientes que fueron remitidos al Departamento de Oncología y al Centro de Radioterapia del Hospital de Docente 5-Azar (Gorgan). Todos los pacientes elegibles fueron vistos durante cinco meses en el 2013. Los datos fueron recopilados mediante el Cuestionario del Sentido de la Vida (MiLS). El instrumento contiene 21 preguntas y consta de cuatro dominios: armonía y paz; perspectiva de la vida; confusión y disminución del significado; $y$ beneficios de la espiritualidad. Las puntuaciones del significado total van de un rango de -3 a 17, representando los puntos más el significado favorable de la vida (visión más positiva acerca de la vida). Se calculó el coeficiente de confiabilidad del Alfa de Cronbach (0.87). El programa estadístico SPSS (versión 18) fue usado para el análisis y se aplicaron el t-test independiente y el análisis de varianza unidireccional (ANOVA). El nivel de significación de esta prueba fue 0.05 .
\end{abstract}

From: ${ }^{1}$ Department of Paramedical, Golestan University of Medical Sciences, Gorgan,Gerontology Department, University of Rehabilitation Sciences and Social Welfare, Tehran, Iran, ${ }^{2}$ Medical Education Development Center, Goletsan University of Medical Sciences, Gorgan, Iran, ${ }^{3}$ Goletsan University of Medical Sciences, Gorgan, Iran and ${ }^{4}$ Medical Students Research Committee,
Golestan University of Medical Sciences, gorgan Iran.

Correspondence: Dr M Chehrehgosha, Department of Paramedical, Golestan University of Medical Sciences, Gorgan, Iran. E-mail: chehrehgosha 2008@gmail.com 
Resultados: La edad promedio de los pacientes fue de $48.31 \pm 5.1$ años. El 47.3 por ciento de los pacientes eran varones. El cincuenta y dos por ciento eran residentes urbanos, 34 por ciento de ellos analfabetos, y 78.7 por ciento de los participantes estaban casado. La puntuación promedio del sentido de la vida fue $7.18 \pm 1.99$ de una puntuación de 17. El estado civil $(\mathrm{p}<0.029)$, tipo de régimen de tratamiento $(p<0.012)$, número de hijos $(p<0.018)$, y lugar de residencia $(\mathrm{p}<0.046)$ son estadísticamente significativos y tienen una relación plena con la puntuación total del sentido de la vida.

Conclusión: El sentido de la vida de todos los participantes en el estudio era relativamente bueno, lo cual puede deberse a la cultura islámica, tan rica en conceptos de significado de la vida en todos los ámbitos (salud y enfermedad).

Palabras claves: Pacientes con cáncer, sentido de la vida, espiritualidad, sobreviviente

West Indian Med J 2016; 65 (3): 516

\section{INTRODUCTION}

The cancer caused numerous psychiatric disorders but it has been shown recently that stress has a profound effect on accelerating development and growth of various malignant tumours (3). Cancer changes the life perspective of patients and patients who feel they have such dangerous disease, report more disability, and have much weaker social functioning and mental health problems (4). Concern and depression in cancer patients may also be due to the loss of organ or body function or dependence on others and the loss of their role in society or family (5).

Cancer and its treatment have several dimensions, so along with clinical issues, mental issues are taken into consideration (6). Shocking events of life, such as cancer can cause persons to change their attitude about the meaning of life and affect their coping mechanism. Many patients use religion and spirituality as a strategy to handle the burden of the diagnosis and treatment of the disease. It makes sense, since religion and spirituality give positive emotions that can cope with feelings of depression; hopelessness and purposelessness (7). Psychologists believe that frustration and stress are the most important predictors of idleness and suicide (8).

There are many ways to find the meaning of life such as: love, suffering and doing something for others. According to the Viewpoint of Frankel, treatment should not only guide patients to achieve meaning in their life, but also encourage them to discover the meaning of life in their life. He believed that suffering is one of the sources of spiritual and emotional growth (9). For cancer patients who are in the last stages of their illness, inner peace and spiritual and mental health may be more important than physical health (10). The aim of this study was to evaluate the meaning of life in patients with cancer and its association with demographic and clinical parameters.

\section{SUBJECTS AND METHODS}

In this cross-sectional study, 150 cancer patients referred to Oncology and Shafa radiation center of 5-Azar Gorgan participated during four month in 2013. Inclusion criteria included; age range between 20 and 80 years, not to mention any history of psychological problems, definitive diagnosis of cancer based on information in medical record, awareness about dis- ease, the absence of any other underlying disease and willingness to participate in the study. After obtaining verbal consent of patients to participate in the study, information was received from patients.

The instrument collected demographic and clinical information which contain; age, gender, place of residence, education level, marital status, number of children, employment status, family income, duration of disease, duration of marriage, family history, and type of treatment regimen. To assess the meaning of life in patients MiLs questionnaire (Meaning in Life Scale) was used. This tool includes four aspects: harmony and peace, life perspective, confusion and lessened meaning, and benefits of spirituality, the total of these four aspects, include 21 items. Harmony and peace domain consists of questions 15,17,18,20, life perspective, include questions 1, 3, 6, 7, 9,11,13, confusion and lessened meaning include questions $2,4,5,8,10,12,14$, the benefits of spirituality include questions 16, 19, 21 .

The ratings of each question was 6 point Likert, and each domain score between 1 and 6 . Total Meaning score was calculated as follows (peace, life perspective and confusion and benefits of spirituality) - (lessened meaning). Total Meaning scores range between -3 to 17 , the higher points, represent the favourable meaning of life [positive view of life] (11). Jim and his colleagues studied the reliability of this instrument by use of Cronbach's alpha coefficient and obtained 0.93 (11). This instrument was translated into Persian and face validity was surveyed by a panel of experts and its reliability was also obtained by Cronbach's alpha (0.87). For entering and analysing data Spss version 18 was used. After confirming the normality distribution of the data with Kolmogorov-Smirnov test, the descriptive statistics used for describe the demographic and clinical variables and $t$-test, analysis of variance (ANOVA) were used for analytical analysis. After the check of homogeneity of variance in ANOVA, with Leven test, Tukey post hoc test was used. The significance level for all tests was considered 0.05 .

\section{RESULTS}

The mean age of patients was $48.31 \pm 5.1$ years; 47.3 per cent of patients were males. Fifty-two per cent were urban residents, 34 per cent were illiterate and 78.7 per cent of participants were married. In 55.3 per cent of patients, lower 12 
months past from treatments, in 51.3 per cents surgicalchemotherapy-radiation therapy has been used (Table 1).

Table 1: Demographic and clinical factors based on most frequent in sub groups $(150=\mathrm{n})$

\begin{tabular}{lcc}
\hline \multicolumn{1}{c}{ Variable } & Frequency & Per cent \\
\hline Age (40-60 years of age) & 73 & 48.7 \\
Gender (female) & 79 & 52.7 \\
Place of residence (City) & 78 & 52 \\
Education (illiterate) & 51 & 34 \\
Status of employment (Working) & 80 & 53.3 \\
The level of income (weak) & 64 & 42.7 \\
Marital status (Married) & 128 & 85.3 \\
Marriage duration (30-20 years) & 38 & 52.3 \\
Number of children (3-1 children) & 79 & 52.7 \\
Positive family history (No) & 121 & 80.7 \\
Duration of disease (less than 12 months) & 83 & 55.3 \\
Treatment regime & & \\
(chemotherapy-radiotherapy-surgery) & 77 & 51.3 \\
\hline
\end{tabular}

Average total score of meaning of life was $7.18 \pm 1.99$ from 17 scores. Score of meaning of life in both males and females and also based on the patient's treatment regimen presented in Table 2.

Table 2: Mean scores of meaning of life based on gender

\begin{tabular}{rrrr}
\hline \multicolumn{1}{c}{ Domain } & & Meaning of life & $\boldsymbol{p}$-value \\
\hline Harmony and peace & Male & $1.16 \pm 3.36$ & 0.710 \\
& Female & $1.27 \pm 3.44$ & \\
Life perspective & Male & $0.64 \pm 3.45$ & 0.480 \\
& Female & $0.51 \pm 3.52$ & \\
Purpose and goals & Male & $0.53 \pm 3.39$ & 0.472 \\
& Female & $0.45 \pm 3.33$ & \\
Confusion and lessened & Male & $1.04 \pm 3.76$ & 0.219 \\
meaning & Female & $1.05 \pm 3.55$ & \\
& Male & $1.96 \pm 7.19$ & 0.727 \\
Total score of meaning & Female & $2.03 \pm 7.18$ & \\
\hline
\end{tabular}

By examining of normality distribution of data with Kolmogorov-Smirnov test, parametric test was used for the data analysis. A statistically meaningful relationship was observed in place of residence $(p=0.046)$, marital status ( $p=$ $0.029)$, number of children $(p=0.018)$, type of treatment regimen $(p=0.012)$ with meaning of life. The meaning of life was higher in patients who have been urban residence. The Tukey post hoc test showed that in marital status variable, the sub group of singles have higher score than widowed patients $(p=0.026)$. The difference was statistically significant, meaning of life in single patients was rated much higher. For variable of number of children, the mean score of 1-3 children with $4-6$ children were statistically significant $(p=0.050)$. In patients with a range of $1-3$ children, mean score of meaning of life was higher. Meaning of life in subtypes of surgery with subtypes Surgery-Chemotherapy $(p=0.026)$. The difference was statistically significant. In patients with surgical treatment regimen, meaning of life was higher. Age, gender, education, employment status, duration of marriage, economic status, were not statistical by significant relationships with meaning $(p>0.05)$.

\section{DISCUSSION}

In the present study, the mean total score of meaning of life was $7.18 \pm 1.99$ from 17 scores. No studies have been performed in Iran and in international studies with this tool, other versions of the questionnaire were used. In the study by Fegg and his colleagues, the meaning of life was surveyed with classification form of MiLE (SMiLE), their overall satisfaction level was $77.7 \pm 14.2$ from 100 score and weight of life (importance) was reported $85.7 \pm 9.4$ (12). In another study, Fegg and his colleagues surveyed the meaning of life in cancer patients by use of SMiLE, overall satisfaction level was $83.3 \pm$ 14.8 and weight of life (importance) in patients was $85.6 \pm$ 12.43 (13).

In the study by Stiefel and colleagues, the meaning of life by means of SMiLE, in the area of overall satisfaction in patients with cancer was $85.9 \pm 7.2$ and weight of life (importance and value) $78.1 \pm 15.1$ has been described (14). Lawrence and his colleagues, in their study investigate the meaning of life with the MiLs, meaning of life scores in patients with breast cancer was $12.81 \pm 1.73$ and in women with other cancers $12.05 \pm 2.92$ was reported (15). Reig-Ferrer and his colleagues studied the meaning of life in haemodialysis patients by using of MiLs, mean score of meaning of life was $7.18 \pm 3.62(16)$.

Based on reported score of this study, life seems to have meaning and still colorful in cancer patients, perhaps family support, religious beliefs and Islamic culture played an important role. Results of this study showed that the meaning of life was higher in single patients Jim and colleagues (11) and Lawrence did not report that marital status had a significant relationship with meaning of life (15) but in the study by Stiefel, significant correlations was seen in marital status and meaning of life, in older married patients, higher score was reported (14). Perhaps the major concern for single patients was about their disease while married patients think about their families and their children. The meaning of life was higher in urban areas. Jim and colleagues (11) and Lawrence (15) reported that place of residence had a productive relationship with meaning of life. Living in urban areas, proper access to additional features and services, can lead to change in the patient's condition, treatment, management feasibility access can ultimately affect one's view about the meaning of life.

Another significant factor of this study was the number of children in families: in families with fewer children, the meaning of life was higher. In studies which have been done with content of the meaning of life, this variable was not surveyed on most articles so, providing legible interpreting about results of this study with other studies was difficult, but it may 
be interpreted that in families with more children, patient concerns about their family and their involvement with the disease process affected on the meaning of life.

In clinical characteristics of patients in this study, type of regimen, were reported the only clinical significant factor. In surgical treatment, a higher meaning of life was reported. In the study by Jim and colleagues (11), this relationship was not significant. It seems that the surgical treatment regimen compared with other treatment modalities such as chemotherapy and radiotherapy and combination of regimens significantly lowered the impact of disease on the patient's physical condition and allowed a proper sense of well-being and meaningful life.

Treatment components play a key role in the recovery of cancer patients, but we cannot ignore the role of other sociodemographic factors involved in recovery. Though meaning of life is a subjective component and multi dimensional item, may be affected by many factors, sociodemographic factors along with clinical factors were important in the management of the cancer patients' condition.

\section{ACKNOWLEDGEMENTS}

Researchers are appreciative of all patients who participated in this study and the oncology and radiotherapy center of 5Azar teaching hospital. This article is extracted from a research project approved by the Research Committee of the University Golestan Medical Sciences.

\section{REFERENCES}

1. Rahemi S. What is important for cancer patients: Report of a qualitative study? Nursing Research Journal 2006; 1: 47-57.

2. Bamshad Z, Safikhani F. Assessment of mental health of women with breast cancer. Ahvaz: Ahvaz University of Medical Sciences; 2006. 56 p.

3. Barabadi M. Effect of supportive psychotherapy as a way of reducing mental disorders Cancer Patients [MSc Thesis]. [Tehran]: allameh Tabatabai University; 2004.

4. Juver JP da S, Verçosa N. Depression in patients with advanced cancer and pain. Rev Bras Anestesiol 2008; 58: 287-98.

5. Kangas M, Henry JL, Bryant RA. Posttraumatic stress disorder following cancer: A conceptual and empirical review. Clin Psychol Rev 2002; 22: 499-524.

6. Kahrazei F, Danesh E, Hydarzadegan A. The effect of cognitive-behavioral therapy (CBT) on reduction of psychological symptoms among patients with cancer. Zahedan J Res Med Sci 2012; 14: 112-6.

7. Torkmoghadam L. Evaluate the meaning of life in cancer patients. J Med Ethics 2009; 3: 85-97.

8. Badger T, Segrin C, Dorros SM, Meek P, Lopez AM. Depression and anxiety in women with breast cancer and their partners. Nurs Res 2007; 56: $44-53$.

9. Corey G. Theory \& practice of group counseling. Belmont, CA: Brooks/Cole, Cengage Learning; 2012.

10. Meraviglia MG. Critical analysis of spirituality and its empirical indicators prayer and meaning in life. J Holist Nurs 1999; 17: 18-33.

11. Jim HS, Purnell JQ, Richardson SA, Golden-Kreutz D, Andersen BL. Measuring meaning in life following cancer. Qual Life Res Int J Qual Life Asp Treat Care Rehabil 2006; 15: 1355-71.

12. Fegg MJ, Brandstätter M, Kramer M, Kögler M, Haarmann-Doetkotte S, Borasio GD. Meaning in life in palliative care patients. J Pain Symptom Manage 2010; 40: 502-9.

13. Fegg MJ, Kramer M, L'hoste S, Borasio GD. The Schedule for Meaning in Life Evaluation (SMiLE): validation of a new instrument for meaningin-life research. J Pain Symptom Manage 2008; 35: 356-64.

14. Stiefel F, Krenz S, Zdrojewski C, Stagno D, Fernandez M, Bauer J. Meaning in life assessed with the "Schedule for Meaning in Life Evaluation" (SMiLE): a comparison between a cancer patient and student sample. Support Care Cancer off J Multinatl Assoc Support Care Cancer 2008; 16: 1151-5.

15. Lawrence J. Meaning in life mediates the relationships between physical and social functioning and distress in cancer survivors [Degree of Doctor of Philosophy]. [Ohio]: Ohio State University; 2004. 